\title{
The Role of Pathology in the Era of Personalized (Precision) Medicine: A Brief Review
}

\author{
Semir Vranic ${ }^{1,2, *}$, Zoran Gatalica ${ }^{3}$ \\ ${ }^{1}$ College of Medicine, QU Health, Qatar University, Doha, Qatar, ${ }^{2}$ Biomedical and Pharmaceutical Research Unit, QU Health, \\ Qatar University, Doha, Qatar, ${ }^{3}$ Department of Pathology, Oklahoma University Health Sciences Center, Oklahoma City, OK, \\ United States
}

Correspondence: semir.vranic@gmail.com orsvranic@qu.edu.qa; Tel.: + 9744403 7873; Fax.: + 97444032250

Received: 15 December 2020; Accepted: 22 December 2020

\begin{abstract}
This review provides a brief overview of the state-of-the-art molecular pathology approaches emphasizing the increasingly important pathology role in clinical precision cancer medicine. Recent advances in molecular biology and genetics have tremendously affected the practice of anatomic pathology, gradually transforming it from a morphology-based into a molecularbased discipline. Molecular diagnostics has a long tradition in pathology, especially in clinical pathology. The improvement of methodology for genomic testing in recent years has made it one of the cornerstones of precision cancer medicine. The decisions related to cancer treatments are no longer solely based on the histopathological diagnosis. Various genomic analyses of human cancers are being incorporated into diagnostic and decision-making algorithms. Conclusion. The pathologists continue to play an essential role in developing and implementing molecular and genomic tests in practice and communicate the results and their relevance with clinicians. Such activities are of utmost importance for successfully translating scientific advancements into a benefit to patients ("next-generation pathologists").
\end{abstract}

Key Words: Cancer Therapy - Precision Medicine - Pathology • Diagnostics • Companion Diagnostics.

\section{Introduction}

In the early 19th century, diagnostic pathology was predominantly restricted to a postmortem assessment, and description of macroscopic tumor spread in the dissection room (1). However, pathology's principles and practice changed dramatically with the establishment of light microscopy and histopathologic investigations in the second half of the 19th century by the renowned German pathologist Dr. Rudolf Virchow (1821-1902), who is considered the 'father of modern pathology' Thanks to these advances, it became possible to investigate different microscopic characteristics of various human diseases, including cancer (1).

*ORCID: http://orcid.org/0000-0001-9743-7265
Microscopic classification of tumors has, over the last 100 years, helped in improving the pathologic diagnosis of neoplastic diseases, predicting tumor behavior and thus formulating the prognosis for each case and thus facilitating clinical decision-making. Traditional cancer classification is based on microscopic evaluations, focusing on various clinicopathological features of tumors, such as tumor morphology (type), grade, surgical margins, vascular/lymphatic invasion, lymph node assessment and routine analysis of biomarkers. Pathologists traditionally utilize frozen sections that enable a rapid gross and microscopic tissue analysis and guide surgeons' hands during surgery (e.g., providing provisional diagnosis, assessing surgical margins, and identifying tissue of origins) (2) (Figure 1). However, none of those mentioned above 


\section{Personalized Medicine and Pathology (testing algorithm)}

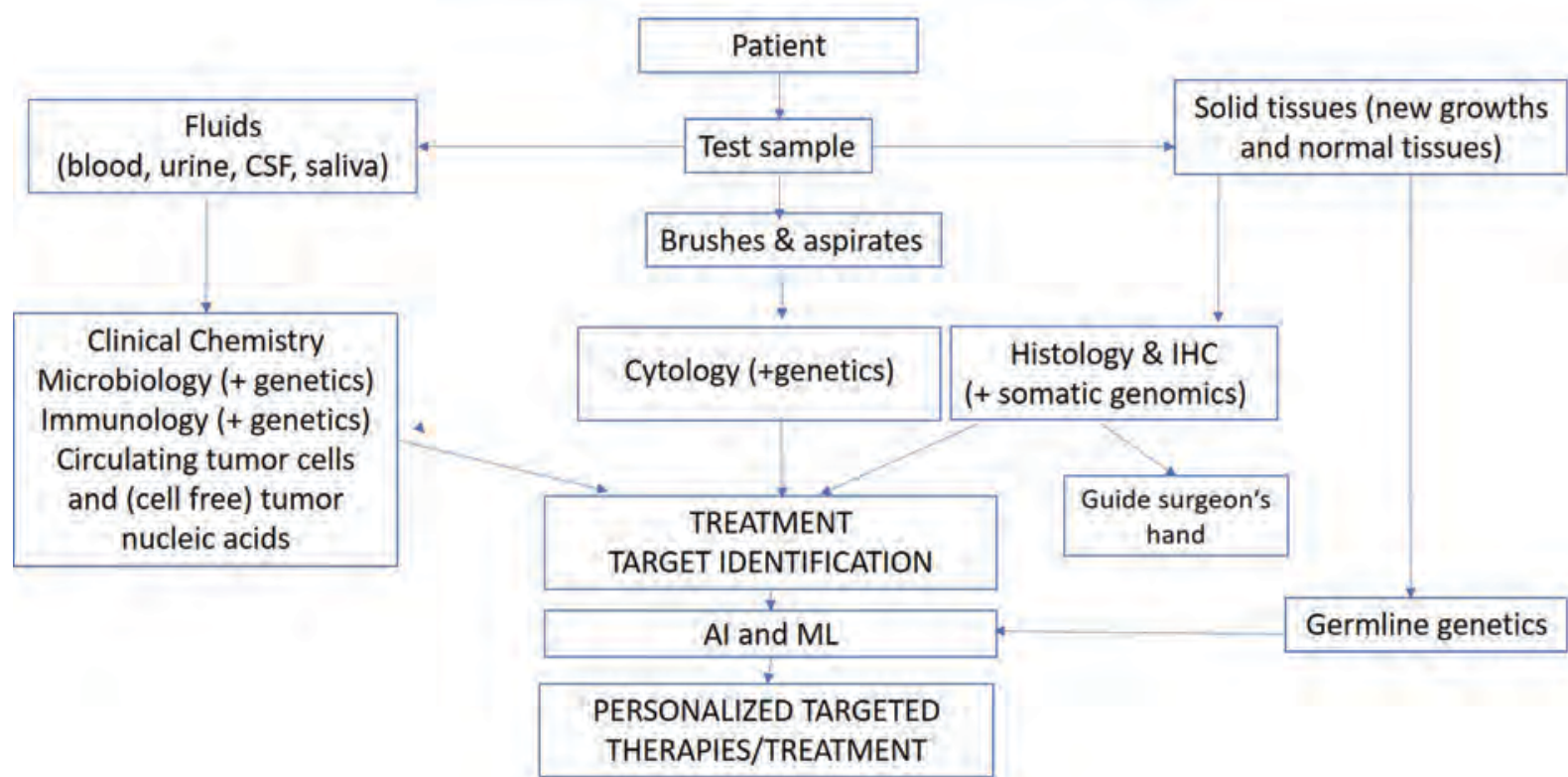

Figure 1. A proposed algorithm for the pathology role in personalized (precision) medicine. CSF=Cerebrospinal fluid; $\mathrm{IHC}=$ Immunohistochemistry; $\mathrm{Al}=$ Artificial intelligence; $\mathrm{ML}=$ Machine learning.

may capture individual cancers' variable clinical courses (heterogeneity).

The underlying basic biology of various cancer and their development and progression are still poorly understood but undoubtedly depend on each tumor's genetic background. The fact that cancer is a genetic disorder was suspected surprisingly early (1914) in the history of cancer research by Dr. Theodor Boveri. He presented a systematic somatic mutation theory of cancer (3). According to Boveri's hypothesis, chromosomal changes caused the transition from normal to the cells' malignant proliferation (3). However, the detailed oncogenesis model was first described by Nowell some 50 years later (4). Dr. Nowell provided evidence that the accumulation of mutations in cancers over time makes them more advanced and aggressive, increasing their metastatic potential. In 2000, Drs. Hanahan and Weinberg elegantly explained detailed cancer evolution in their seminal papers "The hallmarks of cancer" $(5,6)$. The authors outlined the principal biological characteristics of carcinogenesis ("hallmarks of cancer").
These features include not only cell proliferation/ replication, apoptosis, (neo)angiogenesis, downregulation of growth suppressors, invasion/metastasis (5) but also the altered metabolic properties, genomic instability/mutations, escape from immune surveillance, and tumor-promoting inflammation (6). This evolutionary model of carcinogenesis can efficiently explain the complexity and the marked heterogeneity that characterize the vast majority of human cancers (7). Recent findings from high-throughput, multiplex/massively parallel technologies (assays) added important information about the underlying genomic alterations and human cancers' biological events. These findings provide insights into novel treatment modalities and allow for patient stratifications that impact cancer patients' management (7).

In the previous two decades, with the increasing understanding of human cancer's molecular genomic drivers, the number of novel biomarkers and the subsequent development of targeted pharmaceutical treatments have dramatically increased. These changes have strongly influenced 
diagnostic pathology practice, gradually transforming it from morphology-based into molecular-based discipline.

This brief review will discuss and critically assess molecular biology's contributions to diagnostic pathology and precision cancer medicine.

\section{Precision Medicine and Pathology}

The concept of personalized medicine stems from the advances in biotechnology, molecular biology, and genetics. It affects the diagnostic tests that may guide the therapeutic options based on individual (specific) characteristics (1). Using massively parallel, high-throughput technologies, these advances enable detecting minute and precise changes at different molecular (DNA, RNA, protein) levels in enormous quantity and variety and at an everincreasing speed. The methods include DNA/ RNA sequencing, mass spectrometry, microarray technologies, comparative genomic hybridization, digital polymerase chain reaction (PCR), each of which generates an enormous quantity of information called "big data" $(8,9)$.

In the U.S., the Personalized Medicine Coalition defined personalized medicine as the "tailoring of medical treatment to each patient's characteristics. It does not mean that drugs (or medical devices) are developed to be unique to a patient but rather the ability to classify individuals into subpopulations that differ in their susceptibility to a particular disease or their response to a specific treatment. Therefore, the preventive or therapeutic interventions can be concentrated on those who will benefit, sparing expense, and adverse effects for those who will not" (10). On the other hand, the U.S. National Cancer Institute (NCI) defines personalized medicine as "a form of medicine that uses information about a person's genes, proteins, and environment to prevent, diagnose, and treat disease" (11). The key features of personalized medicine include identifying populations (or individual patients) who are candidates for treatment, either by identifying patient/disease characteristics that are likely to benefit or show no improvement/ develop adverse effects from treatment (12). Von
Hoff and collaborators at TGen and Caris Life Sciences were the pioneers in the precision medicine treatment approach, demonstrating that molecular profiling of patients' tumors is an efficient approach to identifying potential targets and selecting the best treatments for their refractory cancers (13). Since then, numerous studies have confirmed the clinical relevance of molecular profiling and personalized medicine in cancer treatment leading to the paradigm shift in cancer treatment (9).

Even though personalized medicine's potential benefits are already evident (e.g., enhanced therapeutic efficacy and increased safety of targeted drugs), its uptake by health care systems varies across the globe. Generally, it remains limited at this time (14). However, it is anticipated that, as a scientific understanding of cancer progresses at the molecular level, personalized medicine approaches to cancer diagnosis and treatment will become more common. For example, the number of personalized medicine devices that have been commercialized in Europe quadrupled between 2006 and 2011 (10). The development of therapeutic products (devices) that are paired with diagnostic tests is also rapidly increasing. In December 2013, the Food and Drug Administration (FDA) approved the first next-generation sequencer (NGS) (Illumina's MiSeqDx) for commercial use in the United States (15). This platform's approval made possible the dozens of genomic information in clinical practice, and markedly expanded this technology's clinical utility to guide patients' care (15). In 2017, the FDA approved the FoundationOne CDx (Foundation Medicine, Inc.) as the first comprehensive, FDA-approved tissue-based companion diagnostic (CDx) assay that is validated for all solid tumors (16). In August 2020, the FDA granted approval for the first liquid biopsy-based NGS CDx test, The Guardant360 CDx (The Guardant Health, Inc.) (17). The Guardant360 CDx utilizes liquid biopsy and NGS technology to detect 55 different genomic alterations, including EGFR gene mutations in patients with NSCLC from circulating cell-free DNA (cfDNA). Besides, several comprehensive NGS-platforms are currently available (e.g., Caris MI profile, Tempus xT assay, 
Invitae Multi-Cancer Panel) (18) and are being increasingly used in cancer decision-making and treatment (19) (please refer to the next paragraph for more details). Recently, the European Society of Medical Oncology (ESMO) Precision Medicine Working up came out with their recommendations for the use of NGS testing for patients with metastatic cancers (20). Using the ESMO Scale for Clinical Actionability of molecular Targets (ESCAT), the ESMO group found concrete evidence. It strongly recommended routine NGS testing for patients with metastatic NSCLC, prostate, ovarian cancers, and cholangiocarcinoma. Besides, they recommended NGS testing for several other common cancers such as colorectal cancer, small cell lung cancer (SCLC), endometrial cancer, neuroendocrine tumors, salivary, thyroid, and vulvar cancers (mainly for the tumor mutational burden (TMB) assessment as a predictive biomarker for immune checkpoint inhibitors) (20).

\section{The Concept of Companion Diagnostic Tests (CDx)}

The rise of precision medicine in pathology accelerated in the 1980s with the diagnostic use of automated immunohistochemistry (IHC) $(21,22)$. Since that time, IHC has been substantially improved, standardized, and its clinical utility in cancer diagnostics has been markedly expanded, particularly in recent years (23-27). IHC is an essential tool for cancer diagnostics and tumor typing (Figure 1). However, it has been increasingly used as a reliable and affordable method for precision medicine purposes. The vast majority of diagnostic tests are developed in the individual laboratories and are designated as a laboratory (or in-house) developed tests (LDT). However, several IHC tests are now designated as "companion diagnostic" or "complementary diagnostic" tests to indicate their status concerning the FDA approval/clearance status. Although IHC is a relatively simple and widely utilized method, frequently fully automated in most pathology laboratories, its interpretation is entirely subjective; hence a strict training/validation processes must be applied.
A companion diagnostic device is defined as "an in vitro diagnostic device (IVD) or an imaging tool that provides information that is essential for the safe and effective use of a corresponding therapeutic product" (28). The use of an IVD companion diagnostic test with a specific therapeutic product is stipulated in the instructions for use in the labeling of both the diagnostic device and the corresponding medicinal product and the labeling of any generic or biosimilar equivalents of the therapeutic product. In other words, a CDx test is required before a specific treatment to determine eligibility. On the other hand, although predictive, a complementary diagnostics test is not needed for the drug's prescription. The concept of precision medicine is accompanied by various CDx tests that have become increasingly approved and used for targeted treatment purposes (29) [a full list of companion diagnostic devices that have been approved by the FDA is available at its website (28)].

One of the earliest CDx relied on the identification of HER2/erbB2 gene amplification (in-situ hybridization) or HER2 protein overexpression (immunohistochemistry) in breast and later in gastric/gastroesophageal junction (GEJ) cancers for the treatment with various anti-HER2 therapeutics such as trastuzumab and pertuzumab (monoclonal antibodies) and lapatinib (a small molecule tyrosine kinase inhibitor that inhibits HER2 specifically) (30-32) (Table 1).

Additional examples of commonly used CDx assays include the assessment of C-KIT (CD117) and PDGFR $\alpha$ mutations in gastrointestinal stromal tumors (GIST) (33), tyrosine kinase mutations affecting the Epidermal growth factor receptor (EGFR) gene, and EML-ALK gene rearrangements in non-small cell lung cancer (NSCLC) (3436 ), and mutations in the BRAF gene in malignant melanoma (37). Notably, most of these genetic alterations have a substantial potential to render tumors susceptible to specific inhibitors mentioned above. In addition to diagnostic PCR or in-situ hybridization-based assays, IHC testing, performed by pathologists, is robust, genomic alteration-specific, cheap, and consequently utilized in a clinical setting. For instance, the ALK 5A4 IHC assay has 
Table 1. Some of the Commonly Used Single Diagnostic Tests [Diagnostic Antibodies (Immunohistochemistry) and Probes (in Situ Hybridization)] with an Approved Status As "Companion Diagnostic" Assays

\begin{tabular}{|c|c|c|c|c|}
\hline $\begin{array}{l}\text { Biomarker/diagnostic assay } \\
\text { (manufacturer) }\end{array}$ & $\begin{array}{l}\text { Scoring } \\
\text { system }\end{array}$ & $\begin{array}{l}\text { Companion diagnostic (CDx) } \\
\text { Thresholds }\end{array}$ & $\begin{array}{l}\text { Indication } \\
\text { (cancer subtype) }\end{array}$ & Drug(s) \\
\hline \multicolumn{5}{|l|}{ Immuno-Oncology (I-O) Biomarkers } \\
\hline 22c3 (DAKO Agilent) & CPS & $<1, \geq 1, \geq 10$ & $\begin{array}{l}\text { Gastric/GEJ } \\
\text { carcinoma, cervical } \\
\text { carcinoma TNBC }\end{array}$ & Pembrolizumab \\
\hline 22c3 (DAKO Agilent) & TPS & $0,1-49, \geq 50$ & NSCLC & Pembrolizumab \\
\hline SP142 (Ventana) & IC scoring & $I C \geq 1 \%, I C \geq 5 \%$ & $\begin{array}{l}\text { TNBC, Urothelial } \\
\text { carcinoma (bladder) }\end{array}$ & Atezolizumab \\
\hline \multicolumn{5}{|c|}{ Other companion diagnostic (CDx) single tests } \\
\hline $\begin{array}{l}\text { ALK Testing } \\
\text { ALK D5F3 Ventana (IHC) }\end{array}$ & $\begin{array}{l}\text { Positive/ } \\
\text { negative }\end{array}$ & $\begin{array}{l}\text { Any percentage of positive } \\
\text { cancer cells }\end{array}$ & NSCLC & $\begin{array}{l}\text { Crizotinib } \\
\text { or ceritinib }\end{array}$ \\
\hline $\begin{array}{l}\text { Vysis ALK Break Apart FISH Probe } \\
\text { Kit (Abbott) (FISH) }\end{array}$ & - & $\begin{array}{l}\text { Identification of } A L K \text { gene } \\
\text { rearrangements with its } \\
\text { partners (e.g., EML4, TFG, KIF5B) }\end{array}$ & NSCLC & $\begin{array}{l}\text { Crizotinib } \\
\text { or ceritinib }\end{array}$ \\
\hline $\begin{array}{l}\text { HER2 testing } \\
\text { anti-HER2 (4B5) (Ventana) (IHC) }\end{array}$ & $\begin{array}{l}\text { Score } \\
0-3+\end{array}$ & Score $3+$ in cancer cells & Breast cancer & $\begin{array}{l}\text { Trastuzumab, } \\
\text { pertuzumab, } \\
\text { adotrastuzumab } \\
\text { emtansine }\end{array}$ \\
\hline $\begin{array}{l}\text { INFORM HER2 Dual ISH DNA Probe } \\
\text { Cocktail (Ventana) (ISH) }\end{array}$ & $\begin{array}{l}\text { HER2/CEP17 } \\
\text { ratio }\end{array}$ & HER2/CEP17 ratio $\geq 2$ (positive) & Breast cancer & $\begin{array}{l}\text { Trastuzumab, } \\
\text { pertuzumab, ado- } \\
\text { trastuzumab emtansine }\end{array}$ \\
\hline DAKO c-Kit PharmDx (IHC) & $\begin{array}{l}\text { Positive/ } \\
\text { negative }\end{array}$ & Any expression in cancer cells & GIST & Imatinib mesylate \\
\hline DAKO EGFR PharmDx (IHC) & $\begin{array}{l}\text { Positive/ } \\
\text { negative }\end{array}$ & $\begin{array}{l}\text { Any membranous expression in } \\
\text { cancer cells }\end{array}$ & Colorectal cancer & $\begin{array}{l}\text { Cetuximab, } \\
\text { panatumumab }\end{array}$ \\
\hline
\end{tabular}

All the listed assays have been approved by the Food and Drug Administration/FDA/ (28). ALK=Anaplastic lymphoma kinase; CEP17=Centromere of chromosome 17; CPS=Combined positive score is defined as the number of PD-L1 positive cells (cancer cells, lymphocytes, and macrophages) divided by the total number of viable tumor cells, multiplied by 100; EGFR=Epidermal growth factor receptor; FISH=Fluorescent in situ hybridization; GEJ=carcinoma Gastroesophageal junction carcinoma; GIST=Gastrointestinal stromal tumor; HER2=Human epidermal growth receptor 2; IC (immune cells) score=A proportion of the tumor area occupied by PD-L1 staining of any intensity; IHC=Immunohistochemistry; ISH=In situ hybridization; NSCLC=Non-small cell lung cancer; $\mathrm{TC}=$ Tumor cells; TNBC=Triple-negative breast cancer; TPS=Tumor proportion score. Defined as the percentage of viable cancer cells showing a partial or complete membrane staining at any intensity.

been confirmed as a reliable screening diagnostic test for ALK-rearranged NSCLCs and is associated with treatment response and survival (38). Similarly, c-Kit expression using c-Kit PharmDx (Agilent) is indicated in both differential diagnosis of gastrointestinal stromal tumors (GIST) (95\% positive) and in selecting the GIST patients that are eligible for treatment with imatinib mesylate (Gleevec). EGFR pharmDxTM is another FDAapproved IHC-based assay that was supposed to identify colorectal cancer patients who are eligible for anti-EGFR-treatment modalities such as cetuximab or panitumumab (Table 1). However, later studies revealed that EGFR protein expression is not a clinically useful predictive biomarker to cetuximab response in patients with CRC $(39,40)$.

Specific biomarkers can also indicate when patients are less likely to respond to a specific therapy, e.g., KRAS or NRAS mutations make colorectal cancers unresponsive to anti-epidermal growth factor receptor (anti-EGFR) therapies such as cetuximab or panitumumab (40-42). Similarly, specific EGFR gene mutations in NSCLC (e.g., point mutation T790M) are responsible for approximately $50 \%$ of acquired resistance to the EGFR tyrosine kinase inhibitors (43).

In contrast to those mentioned above single genomic assays, FoundationOne $\mathrm{CDx}$ is the first FDA-approved comprehensive tissue-based CDx 
that has been validated in a variety of solid tumors. It includes a broad panel of tested genes $(\mathrm{N}=324)$ and two genomic signatures. It has already been utilized in treatment decision-making for various solid cancers, including NSCLC, colorectal, breast, ovarian cancer, and malignant melanoma (44) (Table 2). The test also provides microsatellite instability (MSI) and tumor mutational burden (TMB) status, both of which are essential predictive biomarkers in immuno-oncology (I-O) treatment regardless of the tumor histology ("tumor agnostic approach") (please refer to the next paragraph). The FoundationOne CDx is also a CDx for identifying the neurotrophic receptor tyrosine kinase (NTRK) genes (NTRK1, NTRK2, and NTRK3) fusions. All the patients whose cancers harbor any of these fusions and regardless of the tumor histotype are eligible for the treatment with an NTRK inhibitor (entrectinib or larotrectinib) (Another "tumor agnostic approach") (45). FoundationOne Liquid CDx is a similar FDA-approved CDx that explores potentially targetable genes using a simple blood sample (liquid biopsy, which is based on peripheral blood analysis of cell-free circulating tumor DNA). It is along with the Guardant360 CDx, the only comprehensive FDA-approved blood-based test that analyzes $>300$ genes, making it the most comprehensive FDA-approved liquid biopsy CDx currently available (Table 2). Besides, FoundationOne Liquid CDx provides blood tumor mutational burden (bTMB), MSI, and tumor fraction values. Another FDA-approved comprehensive molecular genomic assay is the MSK-IMPACT ${ }^{\mathrm{Tm}}$ test developed by the Memorial Sloan Kettering Cancer Center. Memorial Sloan Kettering-Integrated Mutation Profiling of Actionable Cancer Targets (MSK-IMPACT) covers 468 different genes, many of which are potentially targetable with currently available drugs (46). MSK-IMPACT has been shown to reliably profile tumor DNA for somatic mutations in various solid malignancies with high accuracy and sensitivity (47). In contrast to the FoundationOne $\mathrm{CDx}$, this assay is mainly used in the United States.

Immunotherapy, based on immune checkpoint inhibitors against programmed cell death protein 1 /programmed death-ligand 1 (PD-1/PD-L1) axis, has dramatically changed the cancer treatment paradigm and improved the outcomes of several common cancers such as melanoma, NSCLC, renal, urothelial, cervical, gastric/gastroesophageal (GEJ), head and neck squamous cell and triplenegative breast carcinomas (TNBC) (48). The therapeutic breakthroughs have been followed by the development of predictive biomarkers of response to immune checkpoint inhibitors. Several of these biomarkers have been validated and achieved a companion diagnostic status, including PD-L1 expression in tumor (T.C.) or immune cells (IC) tested by IHC. Tumor mutational burden (TMB) and microsatellite instability-high (MSI-H) status, determined by NGS-based assays, have also been approved as predictive biomarkers to immune checkpoint blockade (e.g., pembrolizumab) (49) (Table 2). Other potential predictive biomarkers [e.g., PD-1 status, PD-L1 (CD274 gene) amplification], although extensively studied, have not been fully validated and consequently approved as CDx assays.

Multiple IHC assays with different scoring algorithms have been approved for various immune checkpoint blockade therapies and associated cancers (Table 1). Several of these IHC assays have been approved as CDx, such as VENTANA SP142 assay for selecting NSCLC, bladder, and TNBC patients for the treatment with immune checkpoint inhibitor atezolizumab. DAKO 22C3 pharmDx assay has been approved for testing eligibility of NSCLC, TNBC, gastric/GEJ, cervical, urothelial, head and neck squamous cell (HNSCC), and esophageal squamous cell carcinoma patients for the treatment with pembrolizumab while DAKO 28-8 pharmDx clone is utilized for the selection of NSCLC patients for the combined treatment with two immune checkpoint inhibitors: nivolumab (against PD-1) + ipilimumab (targeting cytotoxic T-lymphocyte-associated protein 4/CTLA-4/) (28). Notably, each of these assays has different scoring algorithms, e.g., tumor proportion score (TPS), combined positive score (CPS), and immune cells (I.C.) score, all of which have different thresholds for positivity. These issues make the current PD-L1 IHC testing landscape very compli- 
Table 2. Overview of the Commonly Used and FDA-Approved Comprehensive Companion Diagnostic Tests

\begin{tabular}{|c|c|c|c|c|}
\hline Assay ${ }^{*}$ & Technology & Gene panel $^{+}$ & Indications $^{\ddagger}$ & Drugs \\
\hline $\begin{array}{l}\text { FoundationOne } \\
\mathrm{CDx}^{\S}\end{array}$ & NGS-based & $\begin{array}{l}324 \text { targetable } \\
\text { Genes } \\
\text { MSI status } \\
\text { TMB status }\end{array}$ & $\begin{array}{l}\text { Multiple cancers (NSCLC, colon, } \\
\text { breast, ovary, melanoma) }\end{array}$ & $\begin{array}{l}21 \text { FDA-approved targeted } \\
\text { therapies }\end{array}$ \\
\hline $\begin{array}{l}\text { FoundationOne } \\
\text { Liquid CDx\| }\end{array}$ & NGS-based & $\begin{array}{l}300 \text { targetable genes } \\
\text { MSI status } \\
\text { Blood TMB status }\end{array}$ & $\begin{array}{l}\text { Multiple } \\
\text { cancers }\end{array}$ & $\begin{array}{l}\text { Multiple targeted } \\
\text { drugs }\end{array}$ \\
\hline MSK-IMPACT ${ }^{\S}$ & NGS-based & $\begin{array}{l}468 \text { targetable genes } \\
\text { MSI status }\end{array}$ & $\begin{array}{l}\text { Multiple } \\
\text { cancers }\end{array}$ & Multiple targeted drugs \\
\hline $\begin{array}{l}\text { The Guardant360 } \\
\text { CDx\| }\end{array}$ & NGS-based & $\begin{array}{l}55 \text { targetable genes, } \\
\text { including EGFR }\end{array}$ & $\begin{array}{l}\text { NSCLC and } \\
\text { other cancers }\end{array}$ & $\begin{array}{l}\text { TAGRISSO (Osimertinib) and } \\
\text { other targeted drugs }\end{array}$ \\
\hline
\end{tabular}

"Manufacturer; ${ }^{\dagger}$ Predictive biomarkers; ${ }^{\ddagger}$ Cancer subtypes; ${ }^{5}$ Tissue-based assay; "Based on peripheral blood analysis of cell-free circulating tumor DNA (cfDNA) (=liquid biopsy); EGFR=Epidermal Growth Factor Receptor; FDA=Food and Drug Administration; MSI=Microsatellite instability; NGS=Next-generation sequencing; $\mathrm{NSCLC}=$ Non-small cell lung cancer; $\mathrm{TMB}=$ Tumor mutational burden

cated. They require pathologists to be specifically trained for each of the proposed assays and their respective scoring systems.

Besides, PD-L1 status in cancer is substantially challenged by its complex regulation within the tumor parenchyma and microenvironment (immune cells), its dynamic clonal and proteomic changes to therapy, heterogeneous host immune defects, and markedly variable standardization among sample preparation and reporting (48). Despite all the advances mentioned above, there is still an unmet need to optimize predictive I-O biomarkers given their limited clinical utility (a low response rate/ resistance in most cancers) and highly demanding testing and interpretation algorithms (20).

\section{Challenges Ahead: "Next-Generation Pathologists" and Precision Medicine}

Molecular pathology has become one of the cornerstones of precision cancer medicine. This change has required enormous efforts from pathologists to gain and demonstrate expertise and skills in this rapidly evolving era (50). Simultaneously, the paradigm shift allowed for the discipline of pathology to reinvent itself as a leading diagnostic discipline in the precision medicine era. Indeed, this would imply additional and continuous efforts to educate pathologists in using genomic and molecular data and interpret novel diagnostic tests and proce- dures. Therefore, the dissemination of knowledge on molecular pathology among pathologists by incorporating the courses in postgraduate training programs for trained pathologists and improving pathology residency training programs are critical for the future of diagnostic molecular pathology (51). In this regard, several countries have already taken the necessary measures. Thus, the Dutch Society of Pathology has launched a 2-year training program in molecular pathology, while the Royal College of Pathologists has a fellowship in molecular pathology for clinical scientists. In the United States, the Association of Molecular Pathology has also developed a molecular pathology curriculum for medical laboratory scientists (52). At the same time, the American Board of Pathology offers certification for the pathologist completing at least 12 months of training in an ACGME (The Accreditation Council for Graduate Medical Education) accredited molecular genetic pathology program (53).

Another essential aspect in which the pathologists play a crucial role is developing and implementing molecular tests in clinical practice and communicating the obtained results with other diagnostic disciplines (e.g., microbiology, clinical chemistry, genetics, and immunology) (15, 54-56) and clinicians (Figure 1). Pathologists also play a crucial role in optimizing the samples for molecular profiling. They are also responsible for the proper and selective use of the available specimens 
to enhance predictive tests' clinical utility. New, complementary diagnostic methods have also been launched, e.g., the sequence analysis of cellfree tumor DNA isolated from plasma or urine (=liquid biopsy) (Figure 1). Liquid biopsy and the traditional tissue samples (biopsy, cytology) are of utmost importance for identifying biomarkers for personalized medicine. Increased availability of diagnostic tests and a growing emphasis on personalized medicine have been approached by the novel, revolutionary technologies such as machine learning (ML) and artificial intelligence (A.I.), both of which could greatly help in analyzing the "big data" and identifying the proper biomarkers for precision medicine (treatment) and diagnostics ("personalized diagnosis") (57, 58) (Figure 1 ). Both methods are rapidly evolving and are believed to contribute to precision medicine and other healthcare fields.

All of the activities mentioned above contribute to a successful translation of the scientific advancements into a benefit to patients ("next-generation pathologists"). In this regard, the European Society of Pathology (ESP) and the Royal College of Pathology (RCPath) groups proposed the guidelines for laboratories performing molecular pathology for cancer patients (52). The guideline encompasses all the essential issues related to molecular pathology testing, including preanalytical considerations, sample receipt and handling (fixation and processing), DNA and RNA extraction, selection of appropriate analytical method(s), and quality control (both internal and external) (52). College of American Pathologists (CAP) has also been actively developing numerous evidencebased guidelines about preanalytical and analytical aspects of diagnostic and molecular pathology. These guidelines also include precision medicine biomarkers and $\mathrm{CDx}$ assays such as estrogen receptor (ER), progesterone receptor (PR) and HER2 (breast cancer), various predictive biomarkers in NSCLC and CRC, biomarkers for prostate cancer, Human Papillomavirus (HPV) testing in HNSCC, etc. (59). Similar initiatives have been taken by international external quality assurance (EQA) agencies [e.g., UK NEQAS ICC \& ISH,
NordiQC, and European Molecular Quality Network (EMQN)], who put joint efforts to publish the guidelines for EQA. These guidelines aim to improve molecular tests' performance for precision medicine purposes (60).

\section{Conclusions and Future Directions}

The practice of diagnostic pathology has been substantially changed in the previous years due to the advances in molecular diagnostics and targeted treatment (precision medicine). Molecular pathology has become one of the cornerstones of precision cancer medicine. Although "the next-generation pathologists" have already been launched, further and continuous educational efforts must fully implement the paradigm shift into diagnostic molecular pathology practice and reinvent it as a leading diagnostic discipline in the precision medicine era. Most of the approved and validated predictive biomarkers in precision medicine still require further optimization and standardization. There is an unmet need for novel and more reliable predictive tests (biomarkers) given a low response rate and common resistance for most approved targeted treatment modalities.

Acknowledgment: We thank Professor Miroslav Harjacek $\mathrm{MD}, \mathrm{PhD}$ (College of Medicine and Health Sciences, Al Ain, United Arab Emirates) for his critical reading and valuable comments.

Conflict of Interest: The authors declare that they have no conflict of interest.

\section{References}

1. Birner P, Prager G, Streubel B. Molecular pathology of cancer: how to communicate with disease. ESMO Open. 2016;1(5):e000085.

2. Rosai J. Guiding the Surgeon's Hand: The History of American Surgical Pathology. 1st ed. Washington, DC: American Registry of Pathology; 1997.

3. Boveri T. Concerning the origin of malignant tumours by Theodor Boveri. Translated and annotated by Henry Harris. J Cell Sci. 2008;121 Suppl 1:1-84.

4. Nowell PC. The clonal evolution of tumor cell populations. Science. 1976;194(4260):23-8. 
5. Hanahan D, Weinberg RA. The hallmarks of cancer. Cell. 2000;100(1):57-70.

6. Hanahan D, Weinberg RA. Hallmarks of cancer: the next generation. Cell. 2011;144(5):646-74.

7. Tsang JYS, Tse GM. Molecular Classification of Breast Cancer. Adv Anat Pathol. 2020;27(1):27-35.

8. Gu J, Taylor CR. Practicing pathology in the era of big data and personalized medicine. Appl Immunohistochem Mol Morphol. 2014;22(1):1-9.

9. El-Deiry WS, Goldberg RM, Lenz HJ, Shields AF, Gibney GT, Tan AR, et al. The current state of molecular testing in the treatment of patients with solid tumors, 2019. CA Cancer J Clin. 2019;69(4):305-43.

10. Personalized Medicine Coalition. [2020 Oct 15]. Available from: http://www.personalizedmedicinecoalition. org/Userfiles/PMC-Corporate/file/pmc_bridgehead_issue_brief_european_reimbursement.pdf.

11. National Cancer Institute. [2020 Oct 15]. Available from: https://www.cancer.gov/publications/dictionaries/cancer-terms/def/personalized-medicine.

12. Food and Drug Administration; [In Vitro Companion Diagnostic Devices]. [2020 Oct 15]. Available from: https://www.fda.gov/regulatory-information/search-fdaguidance-documents/vitro-companion-diagnostic-devices.

13. Von Hoff DD, Stephenson JJ Jr, Rosen P, Loesch DM, Borad MJ, Anthony S, et al. Pilot study using molecular profiling of patients' tumors to find potential targets and select treatments for their refractory cancers. J Clin Oncol. 2010;28(33):4877-83.

14. Chen A, Flaherty K, O’Dwyer PJ, Giantonio B, Marinucci DM, Lee J-W, et al. Tumor Genomic Profiling Practices and Perceptions: A Survey of Physicians Participating in the NCI-MATCH Trial. JCO Precision Oncology. 2020(4):1207-16.

15. Collins FS, Hamburg MA. First FDA authorization for next-generation sequencer. $\mathrm{N}$ Engl J Med. 2013;369(25):2369-71.

16. Foundation Medicine; [FoundationOne CDx]. [2020 Oct 15]. Available from: https://www.foundationmedicine. com/test/foundationone-cdx.

17. FDA approves liquid biopsy NGS companion diagnostic test for multiple cancers and biomarkers: Food and Drug Administration; 2020. [2020 Oct 15]. Available from: https://www.fda.gov/drugs/fda-approves-liquidbiopsy-ngs-companion-diagnostic-test-multiple-cancers-and-biomarkers\#: :text=FDA $\% 20$ approves $\% 20$ liquid\%20biopsy\%20NGS\%20companion\%20diagnostic\%20test\%20for\%20multiple\%20cancers\%20and\%20 biomarkers, - Share\&text $=$ On $\% 20$ October\%2026\%20 and $\% 20$ November,(Foundation $\% 20$ Medicine $\% 2$ C\%20 Inc.).

18. Zeng J, Johnson A, Shufean MA, Kahle M, Yang D, Woodman SE, et al. Operationalization of Next-Generation Se- quencing and Decision Support for Precision Oncology. JCO Clin Cancer Inform. 2019(3):1-12.

19. Freedman AN, Klabunde CN, Wiant K, Enewold L, Gray SW, Filipski KK, et al. Use of Next-Generation Sequencing Tests to Guide Cancer Treatment: Results From a Nationally Representative Survey of Oncologists in the United States. JCO Precision Oncology. 2018(2):1-13.

20. Mosele F, Remon J, Mateo J, Westphalen CB, Barlesi F, Lolkema MP, et al. Recommendations for the use of nextgeneration sequencing (NGS) for patients with metastatic cancers: a report from the ESMO Precision Medicine Working Group. Ann Oncol. 2020;31(11):1491-505.

21. Taylor CR, Burns J. The demonstration of plasma cells and other immunoglobulin-containing cells in formalin-fixed, paraffin-embedded tissues using peroxidase-labelled antibody. J Clin Pathol. 1974;27(1):14-20.

22. Grogan TM. Automated immunohistochemical analysis. Am J Clin Pathol. 1992;98(4 Suppl 1):S35-8.

23. Taylor CR. Milestones in Immunohistochemistry and Molecular Morphology. Appl Immunohistochem Mol Morphol. 2020;28(2):83-94.

24. Taylor CR. Improved and Standardized Approaches to Selection of Control Materials From ISIMM: Announcing a Workshop at the Annual ASCP Meeting, September 6-7, 2017, Sponsored by the International Society for Immunohistochemistry and Molecular Morphology. Appl Immunohistochem Mol Morphol. 2017;25(7):451-2.

25. Torlakovic EE, Cheung CC, D’Arrigo C, Dietel M, Francis GD, Gilks CB, et al. Evolution of Quality Assurance for Clinical Immunohistochemistry in the Era of Precision Medicine. Part 3: Technical Validation of Immunohistochemistry (IHC) Assays in Clinical IHC Laboratories. Appl Immunohistochem Mol Morphol. 2017;25(3):151-9.

26. Torlakovic EE, Cheung CC, D’Arrigo C, Dietel M, Francis GD, Gilks CB, et al. Evolution of Quality Assurance for Clinical Immunohistochemistry in the Era of Precision Medicine - Part 2: Immunohistochemistry Test Performance Characteristics. Appl Immunohistochem Mol Morphol. 2017;25(2):79-85.

27. Cheung CC, D’Arrigo C, Dietel M, Francis GD, Gilks CB, Hall JA, et al. Evolution of Quality Assurance for Clinical Immunohistochemistry in the Era of Precision Medicine: Part 1: Fit-for-Purpose Approach to Classification of Clinical Immunohistochemistry Biomarkers. Appl Immunohistochem Mol Morphol. 2017;25(1):4-11.

28. List of Cleared or Approved Companion Diagnostic Devices (In Vitro and Imaging Tools): Food and Drug Administration. [2020 Oct 15]. Available from: https://www. fda.gov/medical-devices/vitro-diagnostics/list-clearedor-approved-companion-diagnostic-devices-vitro-andimaging-tools.

29. Plones T, Engel-Riedel W, Stoelben E, Limmroth C, Schildgen O, Schildgen V. Molecular Pathology and Personalized Medicine: The Dawn of a New Era in Companion 
Diagnostics-Practical Considerations about Companion Diagnostics for Non-Small-Cell-Lung-Cancer. J Pers Med. 2016;6(1):3.

30. Geyer CE, Forster J, Lindquist D, Chan S, Romieu CG, Pienkowski $\mathrm{T}$, et al. Lapatinib plus capecitabine for HER2-positive advanced breast cancer. N Engl J Med. 2006;355(26):2733-43.

31. Hortobagyi GN. Trastuzumab in the treatment of breast cancer. N Engl J Med. 2005;353(16):1734-6.

32. Baselga J, Bradbury I, Eidtmann H, Di Cosimo S, de Azambuja E, Aura C, et al. Lapatinib with trastuzumab for HER2-positive early breast cancer (NeoALTTO): a randomised, open-label, multicentre, phase 3 trial. Lancet. 2012;379(9816):633-40.

33. Rubin BP, Heinrich MC, Corless CL. Gastrointestinal stromal tumour. Lancet. 2007;369(9574):1731-41.

34. Lynch TJ, Bell DW, Sordella R, Gurubhagavatula S, Okimoto RA, Brannigan BW, et al. Activating mutations in the epidermal growth factor receptor underlying responsiveness of non-small-cell lung cancer to gefitinib. N Engl J Med. 2004;350(21):2129-39.

35. Maemondo M, Inoue A, Kobayashi K, Sugawara S, Oizu$\mathrm{mi} \mathrm{S}$, Isobe $\mathrm{H}$, et al. Gefitinib or chemotherapy for nonsmall-cell lung cancer with mutated EGFR. N Engl J Med. 2010;362(25):2380-8.

36. Soda M, Choi YL, Enomoto M, Takada S, Yamashita $\mathrm{Y}$, Ishikawa $\mathrm{S}$, et al. Identification of the transforming EML4-ALK fusion gene in non-small-cell lung cancer. Nature. 2007;448(7153):561-6.

37. Flaherty KT, Puzanov I, Kim KB, Ribas A, McArthur GA, Sosman JA, et al. Inhibition of mutated, activated BRAF in metastatic melanoma. N Engl J Med. 2010;363(9):80919.

38. Fiset PO, Labbe C, Young K, Craddock KJ, Smith AC, Tanguay J, et al. Anaplastic lymphoma kinase 5A4 immunohistochemistry as a diagnostic assay in lung cancer: A Canadian reference testing center's results in populationbased reflex testing. Cancer. 2019;125(22):4043-51.

39. Licitra L, Storkel S, Kerr KM, Van Cutsem E, Pirker R, Hirsch FR, et al. Predictive value of epidermal growth factor receptor expression for first-line chemotherapy plus cetuximab in patients with head and neck and colorectal cancer: analysis of data from the EXTREME and CRYSTAL studies. Eur J Cancer. 2013;49(6):1161-8.

40. Evaluation of Genomic Applications in Practice and Prevention (EGAPP) Working Group. Recommendations from the EGAPP Working Group: can testing of tumor tissue for mutations in EGFR pathway downstream effector genes in patients with metastatic colorectal cancer improve health outcomes by guiding decisions regarding anti-EGFR therapy? Genet Med. 2013;15(7):517-27.

41. Amado RG, Wolf M, Peeters M, Van Cutsem E, Siena S, Freeman DJ, et al. Wild-type KRAS is required for pani- tumumab efficacy in patients with metastatic colorectal cancer. J Clin Oncol. 2008;26(10):1626-34.

42. Jimeno A, Messersmith WA, Hirsch FR, Franklin WA, Eckhardt SG. KRAS mutations and sensitivity to epidermal growth factor receptor inhibitors in colorectal cancer: practical application of patient selection. J Clin Oncol. 2009;27(7):1130-6.

43. Gazdar AF. Activating and resistance mutations of EGFR in non-small-cell lung cancer: role in clinical response to EGFR tyrosine kinase inhibitors. Oncogene. 2009;28 Suppl 1:S24-31.

44. FoundationOne CDx - P170019: Food and Drug Administration; 2020. [2020 Oct 15]. Available from: https:// www.fda.gov/medical-devices/recently-approved-devices/foundationone-cdx-p170019.

45. FDA Approves Companion Diagnostic to identify NTRK fusions in solid tumors for Vitrakvi: Food and Drug Administration. [2020 Oct 15]. Available from: https://www. fda.gov/drugs/fda-approves-companion-diagnostic-identify-ntrk-fusions-solid-tumors-vitrakvi.

46. MSK-IMPACT: A Targeted Test for Mutations in Both Rare and Common Cancers: Memorial Sloan Kettering Cancer Center. [2020 Oct 15]. Available from: https:// www.mskcc.org/msk-impact.

47. Cheng DT, Mitchell TN, Zehir A, Shah RH, Benayed R, Syed A, et al. Memorial Sloan Kettering-Integrated $\mathrm{Mu}-$ tation Profiling of Actionable Cancer Targets (MSK-IMPACT): A Hybridization Capture-Based Next-Generation Sequencing Clinical Assay for Solid Tumor Molecular Oncology. J Mol Diagn. 2015;17(3):251-64.

48. McKean WB, Moser JC, Rimm D, Hu-Lieskovan S. Biomarkers in Precision Cancer Immunotherapy: Promise and Challenges. Am Soc Clin Oncol Educ Book. 2020;40:e275-e91.

49. Nucleic Acid Based Tests: Food and Drug Administration; 2020. [2020 Oct 15]. Available from: https://www. fda.gov/medical-devices/vitro-diagnostics/nucleic-acidbased-tests.

50. Tonellato PJ, Crawford JM, Boguski MS, Saffitz JE. A national agenda for the future of pathology in personalized medicine: report of the proceedings of a meeting at the Banbury Conference Center on genome-era pathology, precision diagnostics, and preemptive care: a stakeholder summit. Am J Clin Pathol. 2011;135(5):668-72.

51. Fassan M. Molecular Diagnostics in Pathology: Time for a Next-Generation Pathologist? Arch Pathol Lab Med. 2018;142(3):313-20.

52. Cree IA, Deans Z, Ligtenberg MJ, Normanno N, Edsjo A, Rouleau E, et al. Guidance for laboratories performing molecular pathology for cancer patients. J Clin Pathol. 2014;67(11):923-31.

53. Molecular Genetic Pathology: The American Board of Pathology. [2020 Oct 15]. Available from: https://www.ab- 
path.org/index.php/to-become-certified/requirementsfor-certification?id=46.

54. Croxatto A, Prod'hom G, Greub G. Applications of MALDI-TOF mass spectrometry in clinical diagnostic microbiology. FEMS Microbiol Rev. 2012;36(2):380-407.

55. Deurenberg RH, Bathoorn E, Chlebowicz MA, Couto N, Ferdous M, Garcia-Cobos S, et al. Reprint of "Application of next generation sequencing in clinical microbiology and infection prevention". J Biotechnol. 2017;250:2-10.

56. Mellors T, Withers JB, Ameli A, Jones A, Wang M, Zhang $\mathrm{L}$, et al. Clinical Validation of a Blood-Based Predictive Test for Stratification of Response to Tumor Necrosis Factor Inhibitor Therapies in Rheumatoid Arthritis Patients. Network and Systems Medicine. 2020;3(1):91-104.
57. Savage N. How Alis improving cancer diagnostics. Nature. 2020;579(7800):S14-S6.

58. Machine learning in cancer diagnostics. EBioMedicine. 2019;45:1-2.

59. Human Papillomavirus Testing in Head and Neck Carcinomas: College of American Pathologists; 2020. [2020 Oct 15]. Available from: https://www.cap.org/protocolsand-guidelines/cap-guidelines/current-cap-guidelines/ human-papillomavirus-testing-in-head-and-neck-carcinomas.

60. Dufraing K, Fenizia F, Torlakovic E, Wolstenholme N, Deans ZC, Rouleau E, et al. Biomarker testing in oncology - Requirements for organizing external quality assessment programs to improve the performance of laboratory testing: revision of an expert opinion paper on behalf of IQNPath ABSL. Virchows Arch. 2020. 